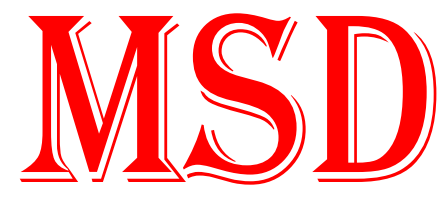

Medical Science and Discovery ISSN: 2148-6832

\title{
Do we need to enlarge emergency services or new emergency hospitals?
}

\author{
Ensar Durmuş $^{1}{ }^{*}$, Fatih Güneysu ${ }^{1}$ \\ 1 Sakarya University Training and Research Hospital Emergency Service, Adapazari, Sakarya, TR \\ * Corresponding Author: Ensar Durmuş E-mail: ensar.durmus@saglik.gov.tr
}

\section{ABSTRACT}

Objective: It was aimed to obtain a notion about the needed hospital bed capacity by analyzing the number of hospitalizations and referrals from the ER in this study.

Material and Method: This study is a retrospective, analytical cross-sectional research. Patients admitted to a tertiary hospital's adult emergency service in 2018-2019, hospitalized, or referred to another hospital were analyzed.

Results: Of the patients, 28036 were hospitalized; furthermore, this number corresponded to 38.4 patients per day. Of these cases, $15303(54.6 \%)$ were male, and the mean age was $57.89( \pm 19.5) ; 8438$ cases $(30.1 \%)$ were admitted to the intensive care unit. The department with the most hospitalizations was internal medicine with 6105 patients (21.78\%) and cardiology, with 4822 hospitalized, the most intensive care patients; moreover, psychiatry had the most prolonged length of stay service average of 28 days. The number of patients required to be hospitalized from the emergency room was an average of 48.5 patients per day. The average hospital stay was seven days.

Conclusion: Mainly in regions with several emergency admissions, it can be considered to establish emergency hospitals that serve particularly emergency cases to engage the number of patients to be hospitalized from the emergency room.

Keywords: Emergency Room, Hospital, Admission

\section{INTRODUCTION}

Emergency services are one of the departments where most patients are examined among the hospital units. According to the National Center for Health Statistics report, several emergency service visits were 130 million (40\% of all population) throughout 2018 in the USA, $12.3 \%$ of the patients who applied to the USA's emergency department were hospitalized; moreover, $2.3 \%$ of them were referred to another hospital (1). According to the Republic of Turkey Ministry of Health data, the just government hospital examination in 2017 was over 90 million in the emergency room; furthermore, this was over $112 \%$ of Turkey's population (2).

\section{Research Article}

Received 01-05-2021

Accepted 15-05-2021

Available Online: 16-05-2021

Published 28-05-2021

Distributed under

Creative Commons CC-BY-NC 4.0

\section{OPEN ACCESS}

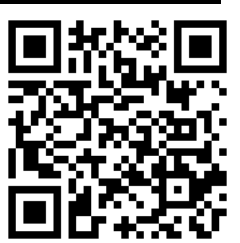

It is inevitable to undergo density in emergency services where so several cases admit. One of the critical reasons for the emergency services' intensity is that the patients continue to stay in the emergency department due to the lack of suitable empty beds, although the patient's emergency room process is over. It has been reported that each surgical case hospitalized increases the waiting period in the emergency department (3). Also, the decrease in the number of discharges contributes to the emergency department's density, reducing the bed capacity (4). The hospital beds are filled with patients hospitalized from the emergency and elective from the polyclinics (5). Therefore, hospital occupancy causes an increase in emergency room density. The emergency services' density, on the other hand, spreads not only the hospital but also the waiting time of the ambulances, generating the entire emergency health system to be adversely affected. Seeking the solution to expand the emergency service might not present the assumed advantages (6).

The increase in the number of emergency admissions brings together the rise in hospitalizations from the emergency department, necessitates the discussion of whether there are sufficient beds in hospitals. 
Reducing the number of unnecessary patients applying to the emergency department may decrease the emergency department's density. However, it can be thought that people with poor health conditions who need to be hospitalized will continue to apply to the emergency department, and as a result, hospitalizations from the emergency department will continue. Therefore, it is essential to examine hospitalizations and referrals from the emergency department.

It was aimed to contribute to the current medical literature and to obtain a notion about the needed hospital bed capacity by analyzing the number of hospitalizations and referrals from the ER in this study. Thus, the answer to the question asked in the title of the article was endeavored.

\section{MATERIAL and METHODS}

Research Type: This study is a retrospective, analytical cross-sectional research.

Definitions: While categorizing the branches in the research, each branch's sub-branch was included in the primary department. Data belonging to general surgery sub-branches such as surgical oncology and gastroenterological surgery were combined with the general surgery branch. The data of hematology, endocrinology, gastroenterology, medical oncology, nephrology, and rheumatology sub-branches were affixed to the internal medicine department's data.

Departments such as otorhinolaryngology, ophthalmology, physical therapy and rehabilitation, and dermatology departments, which the emergency service infrequently consults patients, are assorted under the name of "other branches".

Gynecological oncology data has been included in the gynecology department. The palliative service, which admits patients from the intensive care unit, has been accepted as the anesthesia department's ward.

Inclusion Criteria: Patients aged 18 and over who applied to Sakarya Training and Research Hospital Adult Emergency Service between 01.01.2018-31.12.2019 and were admitted to the hospital's service and intensive care units were included in the research. Moreover, patients who were referred from the adult emergency room to another hospital due to the lack of patient beds were also included in the research.

Exclusion Criteria: Pregnant cases, patients younger than 18 years old, patients admitted to other hospital units, patients with incomplete files were eliminated from the study. The patients left the emergency service by their means, and those who refused treatment were excluded from the study.

Data Collecting: The gender, age, intensive care admission status, the total length of stay in the intensive care unit, wards, and hospital, the departments' name in which the patients were admitted from the emergency department, the mortality data of the patients in the service or intensive care unit were obtained from the patient files and the hospital automation system. Data on patients referred from the SEAH adult emergency department to another hospital due to bed insufficiency was collected.

Statistical Analysis: The data acquired were analyzed with the IBM Statistical Package for the Social Sciences (SPSS) version 21 program. Skewness and Kurtosis values were required to be in the range of $-2 /+2$ for the data's normal distribution (1). Chi-square test was used for comparison of categorical data, and results with $\mathrm{p}<0.05$ were recognized as statistically meaningful. The Mann-Whitney U test was used to compare two independent data groups that were not normally distributed, and the Kruskal Wallis Test was used to analyze more than two independent data groups and results with $\mathrm{p}<0.05$ were regarded significant.

Permission: Approval was obtained from Sakarya Training and Research Hospital Chief Physician's Office on 12.02.2021. Ethical approval was obtained from Sakarya University Medical Faculty, Date: 02.03.2021, No: E71522473-050.01.04-15144-147.

\section{RESULTS}

During the research period, the number of examinations performed in the adult emergency department was 762919 . The rate of all hospitalizations from the emergency room to the hospital was $3.7 \%$, the rate of admission to intensive care was $1.1 \%$, and the rate of referral from the emergency service to another hospital was $1 \%$. Of the patients, 28036 from the SEAH adult emergency room were hospitalized; furthermore, this number corresponded to 38.4 patients per day. Of these cases, $15303(54.6 \%)$ were male, 12733 of them $(45.4 \%)$ were female, the mean age was $57.89( \pm 19.5)$, the median age value was 61 , and the age range was 18-106.

Of these patients, 8438 cases $(30.1 \%)$ were hospitalized from the emergency room to the intensive care unit. The department with the most maximum hospitalizations was internal medicine, with 6105 patients (21.78\%). The cardiology, with 4822 hospitalized the most patients in intensive care. This number was $17.2 \%$ of all emergency hospitalized patients and corresponded to $57.15 \%$ of all intensive care hospitalizations. The anesthesia department, which followed $95.7 \%$ of its patients in intensive care, had the highest intensive care patients rate.

Considering the mortality status, that was determined that the internal medicine department had the highest number of deaths with 1137 , and the anesthesia department had the highest mortality rate, with $70.3 \%$. See Table 1 for gender, intensive care hospitalization, and mortality status of all departments.

Psychiatry had the most prolonged length of stay in service with an average of 28 days (median 24 days), while the most extended hospitalization time in the intensive care unit belonged to the anesthesia with an average of 24 days (median 11 days). See Table 2 for the patients' service and intensive care stay periods according to all departments.

Looking at the statistical analysis: There was a significant discrepancy in mortality between the genders; furthermore, $12.8 \%$ of men and $10.8 \%$ of women died $(p=0.001)$. There is a meaningful distinction between genders and intensive care unit admission, with $35.3 \%$ of men and $23.8 \%$ of women accepted to intensive care $(\mathrm{p}=0.001)$. There was also a notable variation among genders and hospitalized departments $(\mathrm{p}=0.001)$. While women were hospitalized more in psychiatry, gynecology, and internal medicine branches, men were hospitalized increased in all other units. 
Table 1. Distribution of patients according to the branches

\begin{tabular}{|c|c|c|c|c|c|c|c|c|c|c|c|c|c|}
\hline & \multicolumn{4}{|c|}{ Gender } & \multicolumn{5}{|c|}{ ICU State $^{1}$} & \multicolumn{4}{|c|}{ Mortality Status ${ }^{2}$} \\
\hline & \multicolumn{2}{|c|}{ Male } & \multicolumn{2}{|c|}{ Female } & \multirow[b]{2}{*}{ Total } & \multicolumn{2}{|c|}{ No } & \multicolumn{2}{|c|}{ Yes } & \multicolumn{2}{|c|}{ Alive } & \multicolumn{2}{|c|}{ Ex } \\
\hline & Count & $\%^{3}$ & Count & $\%^{3}$ & & Count & $\%^{3}$ & Count & $\%^{3}$ & Count & $\%^{3}$ & Count & $\%^{3}$ \\
\hline Internal medicine & 2960 & $48.5 \%$ & 3145 & $51.5 \%$ & 6105 & 5095 & $83.5 \%$ & 1010 & $16.5 \%$ & 4968 & $81.4 \%$ & 1137 & $18.6 \%$ \\
\hline Cardiology & 3899 & $68.5 \%$ & 1791 & $31.5 \%$ & 5690 & 868 & $15.3 \%$ & 4822 & $84.7 \%$ & 5087 & $89.4 \%$ & 603 & $10.6 \%$ \\
\hline General surgery & 1958 & $56.1 \%$ & 1532 & $43.9 \%$ & 3490 & 3129 & $89.7 \%$ & 361 & $10.3 \%$ & 3193 & $91.5 \%$ & 297 & $8.5 \%$ \\
\hline Neurology & 1669 & $51.4 \%$ & 1580 & $48.6 \%$ & 3249 & 2608 & $80.3 \%$ & 641 & $19.7 \%$ & 2898 & $89.2 \%$ & 351 & $10.8 \%$ \\
\hline Orthopedics & 1371 & $58.2 \%$ & 984 & $41.8 \%$ & 2355 & 2031 & $86.2 \%$ & 324 & $13.8 \%$ & 2199 & $93.4 \%$ & 156 & $6.6 \%$ \\
\hline Gynecology & 0 & $.0 \%$ & 1823 & $100.0 \%$ & 1823 & 1803 & $98.9 \%$ & 20 & $1.1 \%$ & 1817 & $99.7 \%$ & 6 & $.3 \%$ \\
\hline Pulmonology & 989 & $60.7 \%$ & 639 & $39.3 \%$ & 1628 & 1015 & $62.3 \%$ & 613 & $37.7 \%$ & 1284 & $78.9 \%$ & 344 & $21.1 \%$ \\
\hline Thoracic surgery & 771 & $78.2 \%$ & 215 & $21.8 \%$ & 986 & 863 & $87.5 \%$ & 123 & $12.5 \%$ & 928 & $94.1 \%$ & 58 & $5.9 \%$ \\
\hline Others branches & 587 & $72.1 \%$ & 227 & $27.9 \%$ & 814 & 779 & $95.7 \%$ & 35 & $4.3 \%$ & 764 & $93.9 \%$ & 50 & $6.1 \%$ \\
\hline Infectious Diseases & 384 & $50.1 \%$ & 383 & $49.9 \%$ & 767 & 686 & $89.4 \%$ & 81 & $10.6 \%$ & 685 & $89.3 \%$ & 82 & $10.7 \%$ \\
\hline Neurosurgery & 349 & $69.0 \%$ & 157 & $31.0 \%$ & 506 & 399 & $78.9 \%$ & 107 & $21.1 \%$ & 431 & $85.2 \%$ & 75 & $14.8 \%$ \\
\hline Psychiatry & 106 & $46.9 \%$ & 120 & $53.1 \%$ & 226 & 222 & $98.2 \%$ & 4 & $1.8 \%$ & 222 & $98.2 \%$ & 4 & $1.8 \%$ \\
\hline $\mathrm{CVS}^{4}$ & 151 & $71.2 \%$ & 61 & $28.8 \%$ & 212 & 92 & $43.4 \%$ & 120 & $56.6 \%$ & 173 & $81.6 \%$ & 39 & $18.4 \%$ \\
\hline Anesthesia & 109 & $58.9 \%$ & 76 & $41.1 \%$ & 185 & 8 & $4.3 \%$ & 177 & $95.7 \%$ & 55 & $29.7 \%$ & 130 & $70.3 \%$ \\
\hline Total & 15303 & $54.6 \%$ & 12733 & $45.4 \%$ & 28036 & 19598 & $69.9 \%$ & 8438 & $30.1 \%$ & 24704 & $88.1 \%$ & 3332 & $11.9 \%$ \\
\hline $\begin{array}{l}{ }^{1} \text { The patient's state } \\
{ }^{2} \text { Mortality status aft } \\
{ }^{3} \text { Percentage in the r } \\
{ }^{4} \text { Cardiovascular sur }\end{array}$ & t bran & intensiv & 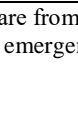 & emerger & & & & & & & & & \\
\hline
\end{tabular}

Table 2. Patients' duration of hospitalization according to the branches

\begin{tabular}{lccccccccc} 
& \multicolumn{3}{c}{ Length of Stay in Service } & \multicolumn{3}{c}{ Length of Stay in ICU } & \multicolumn{3}{c}{ Total Lenght of Stay in Hospital } \\
Branches & Count & Mean & Median & Count & Mean & Median & Count & Mean & Median \\
\hline Anesthesia & 8 & 9 & 11 & 177 & 24 & 11 & 185 & 25 & 12 \\
Neurosurgery & 399 & 3 & 2 & 107 & 11 & 4 & 506 & 6 & 3 \\
Infectious Diseases & 686 & 7 & 6 & 81 & 9 & 5 & 767 & 8 & 6 \\
General surgery & 3129 & 4 & 3 & 361 & 6 & 3 & 3490 & 5 & 3 \\
Thoracic surgery & 863 & 7 & 5 & 123 & 4 & 2 & 986 & 8 & 6 \\
Pulmonology & 1015 & 9 & 8 & 613 & 11 & 6 & 1628 & 12 & 8 \\
Internal medicine & 5095 & 5 & 3 & 1010 & 8 & 4 & 6105 & 6 & 4 \\
Gynecology & 1803 & 3 & 2 & 20 & 9 & 1 & 1823 & 3 & 2 \\
Cardiovascular & 92 & 15 & 5 & 120 & 4 & 2 & 212 & 13 & 5 \\
surgery & & & & & & & & & \\
Cardiology & 868 & 4 & 3 & 4822 & 3 & 2 & 5690 & 5 & 3 \\
Neurology & 2608 & 6 & 5 & 641 & 14 & 5 & 3249 & 8 & 5 \\
Orthopedics & 2031 & 7 & 5 & 324 & 7 & 3 & 2355 & 8 & 6 \\
Psychiatry & 222 & 28 & 24 & 4 & 17 & 3 & 226 & 28 & 24 \\
Others branches & 779 & 5 & 3 & 35 & 3 & 2 & 814 & 5 & 4 \\
Total & 19598 & 5.4 & 4 & 8438 & 6 & 2 & 28036 & 7 & 4 \\
\hline
\end{tabular}

Table 3. Patients' statistics

\begin{tabular}{|c|c|c|c|c|c|c|c|}
\hline & Service Duration & ICU Duration & Total Duration & Gender & ICU Status $^{1}$ & Mortality $^{2}$ & Branches \\
\hline Gender & $\mathrm{p}=0.163^{\mathrm{a}}$ & $\mathrm{p}=0.001^{\mathrm{a}}$ & $\mathrm{p}=0.001^{\mathrm{a}}$ & N/A & $\mathrm{p}=0.001^{\mathrm{b}}$ & $\mathrm{p}=0.001^{\mathrm{b}}$ & $\mathrm{p}=0.001^{\mathrm{b}}$ \\
\hline ICU Status & N/A & N/A & $\mathrm{p}=0.001^{\mathrm{a}}$ & $\mathrm{p}=0.001^{\mathrm{b}}$ & N/A & $\mathrm{p}=0.001^{\mathrm{b}}$ & $\mathrm{p}=0.001^{\mathrm{b}}$ \\
\hline Mortality & $\mathrm{p}=0.001^{\mathrm{a}}$ & $\mathrm{p}=0.001^{\mathrm{a}}$ & $\mathrm{p}=0.001^{\mathrm{a}}$ & $\mathrm{p}=0.001^{\mathrm{b}}$ & $\mathrm{p}=0.001^{\mathrm{b}}$ & N/A & $\mathrm{p}=0.001^{\mathrm{b}}$ \\
\hline Branches & $\mathrm{p}=0.001^{\mathrm{c}}$ & $\mathrm{p}=0.001^{\mathrm{c}}$ & $\mathrm{p}=0.001^{\mathrm{c}}$ & $\mathrm{p}=0.001^{\mathrm{b}}$ & $\mathrm{p}=0.001^{\mathrm{b}}$ & $\mathrm{p}=0.001^{\mathrm{b}}$ & N/A \\
\hline 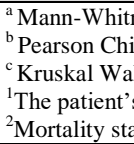 & $\begin{array}{l}\text { test results } \\
\text { are test results } \\
\text { est results } \\
\text { nsive care unit admissio } \\
\text { f the patient }\end{array}$ & & & & & & \\
\hline
\end{tabular}

A critical relationship was found between mortality and hospitalization in intensive care $(\mathrm{p}=0.001)$. While $7 \%$ of the cases who were not admitted to the intensive care unit died, $23.1 \%$ of the patients hospitalized in the intensive care unit died. A significant deviation was found within mortality and departments $(p=0.001)$. Thus, anesthesia was perceived to have the most extraordinary mortality rate with $70.3 \%$, pulmonology $21.1 \%$, internal medicine $18.6 \%$, cardiovascular surgery $18.4 \%$.

While gender had no significant impact on hospital stay duration $(p=0.163)$, it was observed that it significantly influenced intensive care duration and total days of hospital stay $(\mathrm{p}=0.001)$.
Hence, men stayed in the intensive care unit and hospital for a more sustained whole time.

Staying in intensive care had a stimulating effect on the whole hospitalization days $(\mathrm{p}=0.001)$; moreover, the total length of stay in the intensive care unit was prolonged. See Table 3 for statistical outcomes.

The referring from the emergency department cases' number was 7391 due to insufficient hospital bed capacity. This situation confirmed that an average of 10.1 patients per day was referred to another hospital. It was ascertained that the branch where the highest number of patients were transferred from the emergency department was cardiology, with 2372 cases. See Table 4 for patient referral data. 
Table 4. Adult patient referrals from the emergency department to other hospitals

\begin{tabular}{|lcccc}
\hline Branches $^{1}$ & \multicolumn{2}{c}{ Referrals From Emergency Room } \\
& $\begin{array}{c}\text { Median } \\
\text { Age }\end{array}$ & $\begin{array}{c}\text { Male } \\
\text { Count }\end{array}$ & $\begin{array}{c}\text { Female } \\
\text { Count }\end{array}$ & $\begin{array}{c}\text { Total } \\
\text { Count }\end{array}$ \\
\hline Anesthesia & 74 & 139 & 123 & 262 \\
Neurosurgery & 58 & 117 & 100 & 217 \\
Infectious Diseases & 76 & 112 & 146 & 258 \\
General Surgery & 33 & 258 & 144 & 402 \\
Thoracic Surgery & 55 & 22 & 8 & 30 \\
Pulmonology & 75 & 698 & 498 & 1196 \\
Internal Medicine & 72 & 518 & 598 & 1116 \\
Cardiovascular Surgery & 56 & 11 & 6 & 17 \\
Cardiology & 69 & 1306 & 1066 & 2372 \\
Neurology & 72 & 545 & 606 & 1151 \\
Orthopedics & 51 & 66 & 27 & 93 \\
Psychiatry & 37 & 165 & 31 & 196 \\
Others Branches & 39 & 32 & 8 & 40 \\
Emergency Medicine & 72 & 22 & 19 & 41 \\
Total & $\mathbf{7 0}$ & $\mathbf{4 0 1 1}$ & $\mathbf{3 3 8 0}$ & $\mathbf{7 3 9 1}$ \\
\hline
\end{tabular}

${ }^{1}$ The branch of the physician decides to refer the patient from the emergency department to another hospital.

Table 5. Number of patients required to be hospitalized

\begin{tabular}{|lcccc|}
\hline Branches & Referral Count & Inpatient Count $^{2}$ & Total Count $^{3}$ & Number Per Day $^{4}$ \\
\hline Anesthesia & 262 & 185 & 447 & 0.6 \\
\hline Neurosurgery & 217 & 506 & 723 & 1 \\
\hline Infectious Diseases & 258 & 767 & 1025 & 1.4 \\
General Surgery & 402 & 3490 & 3892 & 5.3 \\
Thoracic Surgery & 30 & 986 & 1016 & 1.4 \\
\hline Pulmonology & 1196 & 1628 & 2824 & 3.9 \\
\hline Internal Medicine & 1116 & 6105 & 7221 & 9.9 \\
\hline Cardiovascular Surgery & 17 & 212 & 229 & 0.3 \\
Cardiology & 2372 & 5690 & 8062 & 11 \\
\hline Neurology & 1151 & 3249 & 4400 & 6 \\
Orthopedics & 93 & 2355 & 2448 & 3.4 \\
\hline Psychiatry & 196 & 226 & 422 & 0.6 \\
\hline Gynecology & 0 & 1823 & 1823 & 2.5 \\
\hline Others Branches & 40 & 814 & 854 & 1.2 \\
\hline Emergency Medicine & 41 & 0 & 41 & 0.1 \\
Total & $\mathbf{7 3 9 1}$ & $\mathbf{2 8 0 3 6}$ & $\mathbf{3 5 4 2 7}$ & $\mathbf{4 8 . 5}$ \\
\hline
\end{tabular}

${ }^{1}$ Number of patients transferred from the emergency department to another hospital

${ }^{2}$ Number of patients hospitalized from the emergency department

${ }^{3}$ Total number of patients requiring hospitalization from the emergency department

${ }^{4}$ Average number of patients that should be hospitalized from the emergency department per day

Briefly, when the number of patients required to be hospitalized from the emergency room was checked, it was remarked that the cumulative number of cases who were hospitalized and referred from the emergency room was 35427. This number corresponds to an average of 48.5 patients per day. See Table 5 for a summary of patients requiring the hospitalization.

\section{DISCUSSION}

Sultanoglu et al. (7) reported that $6318(8.4 \%)$ of the patients who applied to a tertiary hospital's emergency service within one year were hospitalized, and $0.4 \%$ were referred. Erkuran et al. (8) reviewed the emergency room patients and noticed that 2380 of these patients $(1.2 \%)$ were hospitalized to ICU from the emergency department, and 66 of them (2.8\%) died in ICU. On the other hand, Groenland et al. (9) reported that $18.1 \%$ of the cases hospitalized from the emergency department to the intensive care unit died. Furthermore, the hospitalization period's prolongation from the emergency department to the ICU was associated with increased patient mortality.
Simpson et al. (10) stated that $26 \%$ of the patients hospitalized in intensive care were hospitalized from the emergency room, and the mortality rate could stretch to $46.4 \%$ among them.

The medical literature studies reported the density of emergency services and their destructive effects on receiving emergency medical care. Niels et al. (3) found that elective surgical operations and hospital occupancy harmed patients' waiting time in the emergency department. Sun et al. (11) stated that more sick cases were admitted to the emergency department on weekends. Besides, Peter et al. (5) reported that discharge from the hospital on weekends was $50 \%$ less than on weekdays. This situation presents us with more severe patients and fewer hospital beds. Emilie et al. (4) similarly stated that patients' discharge from the hospital services reduces emergency room overcrowding.

\section{When all these above researches are assessed together;}

In this study, the average number of patients requiring daily hospitalization from the ER was 48.5, and the average hospital stay of all patients hospitalized from the emergency 
department was observed to be seven days. Thus, approximately 340 patient beds should be reserved for the patients hospitalized in the emergency department to evade hospital occupancy. Besides, these numbers do not include the patients hospitalized from the pediatric emergency and obstetrics emergency services. Considering that the number of emergency service admissions has risen every year, the number of beds required to suffice the ER hospitalizations suggests that an "emergency hospital" is required separately. Here, an emergency hospital is meant to be a hospital structure where elective hospitalization is not admitted, and all branches work for emergency patients. An increase in the emergency service admissions and the inpatients' numbers obstruct managing emergency services and elective services together, primarily in regions where emergency admissions are intense. In this case, we will come across two options:

Firstly, emergency hospitalizations will interrupt several elective treatments and operations planned before, and these patients will be disrupted due to the continuous hospitalization of patients from the emergency room. Secondly, the patients who require several urgent interventions will be referred to another hospital or wait for hospitalization in the emergency department while the elective cases are hospitalized. Researches in the current medical literature have also determined that elective patients' admissions increase the length of stay in the emergency room. The prolongation of the emergency department's stay will negatively affect the medical care that patients will receive.

The branches with the highest number of hospitalizations from the ER are internal medicine, cardiology, general surgery, neurology, orthopedics, gynecology, and pulmonology; moreover, these have the highest patient rate referred to other hospitals. It is perceived that hospitals should have adequate service and intensive care beds for these branches to provide adequate health care from the ER. Unfortunately, these departments are among the main branches with many outpatients; elective hospitalizations from polyclinics will be confronted with hospitalizations from the ER.

\section{CONCLUSIONS}

The number of emergency service admissions increases worldwide and patients hospitalized from the emergency department has a unique place among all inpatients. Mainly in regions with several emergency admissions, it can be considered to establish emergency hospitals that serve particularly emergency cases in order to engage the number of patients to be hospitalized from the emergency room, to prevent unnecessary waiting and intensity in emergency services, and to decrease the referring patients to another hospital. Oppositely, either emergency treatment services or elective treatment procedures may be obstructed.

Author Contributions: ED, FG: Study design and Data collection, Statistical Analyzes, ED: Article writing and revisions.
Financial \& competing interest's disclosure: The authors have no relevant affiliations or financial involvement with any organization or entity with a financial interest in or financial conflict with the subject matter or materials discussed in the manuscript. This includes employment, consultancies, honoraria, stock ownership or options, expert testimony, grants or patents received or pending, or royalties.

Ethical approval: The study was conducted according to the guidelines of the Declaration of Helsinki and approved by Local Ethical Committee.

Conflict of interest: The authors declared no potential conflicts of interest with respect to the research, authorship, and/or publication of this article. This research did not receive and specific grant from funding agencies in the public, commercial, or not-for-profit sectors.

\section{REFERENCES}

1. "Emergency Department Visits," Available on: https //www.cdc.gov/nchs/fastats/emergency-department.htm (accessed Feb. 12, 2021). Jan. 25, 2021

2. Alper M. "Top 100 Hospitals in Each Branch-2017 Number of Public Hospitals Examination, Hospitalization, Intensive Care, Surgery, Emergency Service and Births.” Türkiye Cumhuriyeti Sağlık Bakanlığı Kamu Hastaneleri Genel Müdürlüğü İstatistik, Analiz, Raporlama ve Stratejik Yönetim Dairesi Başkanlığı, Mar 2017, Accessed: Mar. 12 , 2020. (Online). Available: https: //khgmistatistikdb.saglik.gov.tr/TR,43819/her-bransta-ilk-100-hastane2017-yili-kamu-hastaneleri-muayene-yatis-yogun-bakim-ameliyat-acilservis-ve-dogum-sayilari.html

3. Rathlev NK, Chessare J, Olshaker J, et al. Time series analysis of variables associated with daily mean emergency department length of stay. Ann Emerg Med 2007; 49: 265-71.

4. Powell ES, Khare RK, Venkatesh AK, Van Roo BD, Adams JG, Reinhardt $\mathrm{G}$. The relationship between inpatient discharge timing and emergency department boarding. J Emerg Med 2012; 42: 186-96.

5. McKenna P, Heslin SM, Viccellio P, Mallon WK, Hernandez C, Morley EJ. Emergency department and hospital crowding: causes, consequences, and cures. Clin Exp Emerg Med 2019; 6: 189-95.

6. Han JH, Zhou C, France DJ, Zhong S, Jones I, Storrow AB, Aronsky D. The effect of emergency department expansion on emergency department overcrowding. Acad Emerg Med 2007; 14: 338-43.

7. Sultanoğlu H, Gamsızkan Z, Cangür Ş . Acil Servise Bir Yılda Başvuran Hastalarda Mükerrer Başvuruların İncelenmesi ve Çözüm Önerileri. DÜ Sağlık Bil Enst Derg 2021; 11: 50-55.

8. Erkuran MK, Duran A, Ocak T, Citisli V, Kaya H. The impact of the duration of admission to the emergency room on the mortality of intensive care patients. Niger J Clin Pract 2014; 17: 320-3.

9. Groenland CNL, Termorshuizen F, Rietdijk WJR, et al. Emergency Department to ICU Time Is Associated With Hospital Mortality: A Registry Analysis of 14,788 Patients From Six University Hospitals in The Netherlands. Crit Care Med 2019; 47: 1564-71.

10. Simpson HK, Clancy M, Goldfrad C, Rowan K. Admissions to intensive care units from emergency departments: a descriptive study. Emerg Med J 2005; 22: 423-8

11. Sun J, Girling AJ, Aldridge C, et al. Sicker patients account for the weekend mortality effect among adult emergency admissions to a large hospital trust. BMJ Qual Saf 2019; 28: 223-30 